\title{
Pharmacological Evaluation of Marginally Designed New Profen Analogues SMA Halimi ${ }^{1}$, M Saeed ${ }^{1}$, S Ullah $^{1}$, and KM Khan ${ }^{2}$
}

\begin{abstract}
Objective: Pharmacological evaluate of hydrazide, marginal analogues of naproxen, flurbiprofen and ibuprofen, well established COX inhibitors, with the goal to identifying a Cyclooxygenase (COX) inhibitor(s) with optimum potency and efficacy. The synthesized and characterized analogues were tested for their acute toxicity, anti-inflammatory, analgesic and antipyretic activities as per reported bioassay models. Molecular docking analysis was also performed to predict ligand: protein interactions.
\end{abstract}

Method: Acute toxicity, anti-inflammatory, analgesic and antipyretic activities were performed in accordance with well-established reported bioassay models for the purposes.

Results: No acute toxicity was observed at intraperitoneal doses of 50,100 and $150 \mathrm{mg} / \mathrm{Kg}$ body weight. Biological assays revealed that test compounds -I to -IV have highly significant antiinflammatory and peripheral analgesic activities. Antipyretic test revealed that test compounds I, II, III have highly significant antipyretic activity while IV in the doses of $20 \mathrm{mg}$ and $30 \mathrm{mg}$ has significant and in the dose of $50 \mathrm{mg} / \mathrm{Kb}$ body weight has highly significant antipyretic activity. The molecular modelling revealed strong inhibitory interactions of the four compounds. The most suitable poses have higher docking score (energies) compared to flurbiprofen (reference ligand), that confirms highly significant anti-inflammatory and analgesic activities of the dimers.

Conclusion: The synthesized hydrazide analogues have highly significant pharmacological activities and have the potential to be further explored as new drug molecules.

Keywords: Analgesic, anti-inflammatory, antipyretic, molecular docking, COX

From: ${ }^{1}$ Department of Pharmacy, University of Peshawar, Peshawar 25120, Pakistan and ${ }^{2}$ HEJ International Centre for Chemical and Biological Sciences (ICCBS), University of Karachi, Karachi 75270, Pakistan.

Correspondence: Dr S Halimi, Department of Pharmacy, University of Peshawar, Peshawar 25120, Khyber Pakhtunkhwa, Pakistan, Fax:+92 91 9218318, e-mail: ashhadhalimi@uop.edu.pk 


\section{INTRODUCTION}

One of the inexhaustible areas for research is the modification of existing drug molecules, which may further be amplified, improved in potency, efficacy, or safety. Development and successful predictions of molecular computation of binding potential between the receptors (proteins) and ligands (drugs) further aided in the efforts of researchers even to design the most appropriate drug structures for both known and unknown proteins, drug discovery $(1,2)$.

Non-steroidal anti-inflammatory drugs (NSAIDs) is a class of drugs, which are the most widely prescribed and used medicines for their anti-inflammatory, analgesic and antipyretics activities. The selection of NSAIDs depends upon the clinical condition of patient, its Cyclooxygenase-1/2 (COX1/COX2) selectivity, duration of use, gastric ulcerative and cardiovascular risks etc., and (3-5). Till today, a number of NSAIDs are being introduced for the treatment of acute and chronic pain, inflammation and pyrexia of different origins, belonging to different chemical classes e.g. salicylates, fenamates, propionates, acetates, oxicams etc. (6) but inflammation, despite of this tremendous advancement in the field of pharmaceutical chemistry still presents a major challenge to the researchers.

Three members of profens, arylpropionic acid class of NSAIDs, i.e. 2(6methoxynaphthalen-2-2yl) propanoic acid (Naproxen) (7), 2-(2-flurobiphenyl-4-yl) propanoic acid (Flurbiprofen) (8); 2-(4(2-methylproply) phenyl) propanoic acid (Ibuprofen) (9) were selected for synthesis of their marginal (hydrazide) analogues to explore their pharmacological activities along with molecular docking analysis to predict its interaction potential, being one of the acceptable tools in drug discoveries (10). In-vivo pharmacological evaluation of the synthesised analogues with molecular docking analysis could provide a useful data for further augmentation of the existing drug molecules for optimal efficacy and safety because there is always a great need 
for better and safer drugs; more active, selective and thus effective drugs with lesser side or toxic effects, for cure, symptomatic treatment or prophylaxis of inflammation and its associated disorders.

\section{MATERIAL AND METHODS}

\section{General}

All chemicals, reagents, and solvents were analytical grade, purchased from commercial suppliers, and used without purification unless otherwise specified. Ibuprofen, flurbiprofen and naproxen were provided by Polyfine Chemipharma (Pvt.) Ltd, Hayatabad, Peshawar, Pakistan. Ethanol and concentrated sulfuric acid were purchased from Sigma-Aldrich, USA), Lambda Carrageenan (Sigma, USA), glacial acetic acid (Panreac, Spain), Brewer yeast (Merck, Germany) and sterile normal saline I/V (Otsuka Japan), used as received.

The purity of the products was checked on thin layer chromatographic plates of aluminum coated with silica gel (Kieselgel 60 F25, Merck, Germany), Melting points on a Bicot apparatus (Bibby Scientific Ltd UK), ${ }^{1} \mathrm{H}$ NMR on Bruker AV 300 and $400 \mathrm{MHz}$ instruments using dimethyl sulfoxide (DMSO) as solvent, Electron impact mass spectra (EI MS) on a "JEOL MS Route" spectrometer (JMS 600-H), Infrared (IR) spectra on a "JASCO IR-A-302" spectrometer, UV spectra on Thermo Electron Vision Pro (V4.10), and C:H:N analyses were determined on a "Carlo ErbaStrumentazione" (Mod-1106) Italy.

Anti-inflammatory activity test was conducted on plethysmometer (Model LE 7500 Plan lab S.L.), anti-nociceptive activity on Hot Plate Analgesiometer (Harvard apparatus, USA) and antipyretic through digital thermometer (Model CA92121, ACON Laboratories, USA. 


\section{Statistical analysis}

GraphPad Prism ${ }^{\circledR}$ (5.01) was used for statistical analysis, in vivo pharmacological activates data were analyzed by applying one-way ANOVA followed by Dunnett's post-hoc analysis.

\section{General procedure for the synthesis of the compounds}

Ibuprofen, naproxen and flurbiprofen were first converted to ethyl ester derivatives through reflux condensation with ethyl alcohol (11). The esters thus synthesized were treated with hydrazine hydrate through reflux condensation, for 24-48 hours, in ethyl alcohol as a solvent medium (12). The completion of reaction was monitored through TLC, using ethyl acetate and hexane as mobile phase. The reactions were completed in 12-18 hrs. The resultant solid products (Table 1) were filtered, washed with hexane (200-400 mL) and distilled water (400-500 mL) and dried.

\section{Pharmacology evaluation}

Mice $(B A L B-c)$, either sex, were used throughout the experimental studies. Animals were purchased from the National Institute of Health $(\mathrm{NIH})$ Islamabad, Pakistan. The animals were kept under the standard laboratory conditions at $25 \pm 2{ }^{\circ} \mathrm{C}$ and fed with standard food ad libitum, free access to drinking water with a $12 \mathrm{hr}$ dark / $12 \mathrm{hr}$ light cycle. Animals' studies were approved by the ethical committee of the Department of Pharmacy, University of Peshawar, Pakistan (No. 01/EC-15/Pharm dated 10-04-2015).

\section{Acute toxicity}

For the toxicity study, the test compounds at the dose of 50,100 and $500 \mathrm{mg} / \mathrm{Kg}$ body weight were administered intraperitoneally (ip) through injection to four groups having six $(n=6)$ mice in each group. While the control group was treated with normal saline. Animal were observed for 6 hours for any behavioural changes while the mortality rates were observed at 24 hours after the administration of test compounds (13). 
Anti-inflammatory Activity Study [Carrageenan-induced paw oedema test]:

Mice were divided into five groups each containing five mice $(\mathrm{n}=6)$. Acute inflammation was induced by injecting $0.05 \mathrm{ml}$ of (1\%) carrageenan into plantar surface of mouse hind paw (14). Test groups I, II, and III were treated with 10,20 and $30 \mathrm{mg} / \mathrm{kg}$ of the test compound, group-IV (control) was treated with normal saline $(1 \mathrm{ml} / \mathrm{kg}$ ) while the Group-V (reference standard) was with Ketoprofen $(10 \mathrm{mg} / \mathrm{kg}), 30 \mathrm{~min}$ before carrageenan injection. The paw volume was measured at $0,1,2,3,4$ and 5 hours using digital plethysmometer. The difference between the readings at time $0 \mathrm{~h}$ and different time interval was taken as the degree of oedema while was quantified as;

$$
\% \text { Inhibition }=\frac{\alpha-\beta}{\alpha} \times 100
$$

Where, $\alpha$ and $\beta$ indicate, increase in paw volume of control and drug-treated animals, respectively.

\section{Evaluation of Anti-Nociceptive Activity}

Acetic acid induced writhing test in mice

Mice were divided into five groups each containing six $(\mathrm{n}=6)$ mice. The test groups, I, II, and III were treated with $10,20,30 \mathrm{mg} / \mathrm{kg}$ body weight, i.p. of the test compound, group IV (control) received normal saline ( $10 \mathrm{ml} / \mathrm{kg}$, i.p.) while the Group-V (reference standard) was treated with diclofenac at the dose of $10 \mathrm{mg} / \mathrm{kg}$, i.p. After 30 minutes of the administration of the aforesaid compounds, normal saline and drug, respectively, all the five groups were treated with $0.6 \%$ acetic acid at $10 \mathrm{ml} / \mathrm{kg}$, i.p. (15). Five minutes after acetic acid injection, mice were placed in individual cages and the numbers of writhes (abdominal contractions) were counted for each mouse for a period of 30 minutes after 5 minutes' latency period, and the percentage inhibition of writhing was calculated. 


\section{Hot plate (thermal) test in mice}

Mice, of either sex, weighing 18-22 g were used in this study. As per protocol, two hours habituated animals to the laboratory environment were randomly divided into five groups, six $(\mathrm{n}=6)$ animals in each group.The test groups I, II, and III were treated with 10, 20, $30 \mathrm{mg} / \mathrm{kg} / \mathrm{i} . \mathrm{p}$. of the test compound, group-IV (control) was treated with normal saline $(10 \mathrm{ml} / \mathrm{kg}$, i.p.) while the Group-V (reference standard) with tramadol at the dose of $5 \mathrm{mg} / \mathrm{kg}$, i.p.The animals were tested after 30 and $60 \mathrm{~min}$ on the hot plate of analgesiometer maintained at temperature of $54.0 \pm 0.1^{\circ} \mathrm{C}$. Hot plate reaction time (latency to response in seconds) was observed by noting licking, flicking of hind limb or jumping from cylinder (16). A cut-off time of 30 secs was fixed for animal's reaction to avoid tissue damage for longer exposure to hot plate. Anti-nociception was calculated using the following formula.

$$
\% \text { Analgesia }=\left(\frac{\text { Test latency }- \text { Control latency }}{\text { Cutoff time }- \text { Control latency }}\right) \times 100
$$

Anti-pyretic Evaluation study (Brewer's yeast induced pyrexia test in mice):

Albino mice $(B A L B-c)$, weighing $25-30 \mathrm{~g}$ of either sex, were used in this study. As per protocol prior to experiments, the animals were fasted overnight with free access to water. The animals were randomly divided into five groups each group consisting of six animals $(\mathrm{n}=6)$. Test groups $\mathrm{I}$, II, and III were treated with 10, 20 and $30 \mathrm{mg} / \mathrm{kg}$ of the test compound, group-IV (control) was treated with normal saline $(10 \mathrm{~mL} / \mathrm{kg})$ while the Group-V (reference standard) was with Paracetamol $(150 \mathrm{mg} / \mathrm{kg})$. Hyperpyrexia was induced by aqueous suspension of $20 \%$ Brewer's yeast ( $10 \mathrm{ml} / \mathrm{kg}$ body weight s.c) below the nape of neck in the back of mice. Changes in rectal temperature were noted after 24 hours of Brewer's yeast injection at 1, 2, 3, 4 and 5 hours (17). For insertion in animal's rectum, probe of digital thermometer was lubricated with olive oil and 
maintained for thirty seconds for recording temperature. Those animals were selected for study that showed a minimum rise of at least $0.3-0.5^{\circ} \mathrm{C}$ rectal temperature.

\section{Molecular docking simulation analysis}

Molecular docking simulates the best-fit orientation of legend (drug) at the specific binding site of a receptor protein that signifies the pharmacological activity and drug designing rational with reference to that very receptor protein (18). COX-2, due to biosynthesis of prostaglandins (PGs), is one of the key enzymes involved in inflammation. Amino acid residues at the binding site (cavity), especially $\operatorname{Arg}_{120}$ and $\mathrm{Tyr}_{355}$ play a central part in designing or virtual screening for discovery of new COX inhibitors (19). Standard docking procedure for rigid protein and a flexible ligand was performed through AutoDock (4.0.1.) (20), along with AutoDock Tools using a Lamarckian generic logarithm. A grid (60x60x60 points) in three dimensions was built, centred on the centre of M loop of Cyclooxygenase-2 (COX2) (PDB ID: 3PGH). A grid spacing of 0.375 $\AA$ and a distance-dependent function of the dielectric constant were used for the calculation of the energy map. Default setting was used for other parameters. The most favorable free binding energy, after successful completion of docking, was selected as resultant ligand protein complex structure (19). To validate the accuracy of the binding mode and binding affinity flurbiprofen was used as a reference and co-crystallized ligand (19).

\section{RESULTS}

\section{Acute toxicity}

No acute toxicity was observed during 24 hours at doses of $50,100,150 \mathrm{mg} / \mathrm{Kg}$ body weight, of all the test compounds. 


\section{Anti-inflammatory activities}

The anti-inflammatory activities data depicted (Figure 1) that TC-II in the dose of $20 \mathrm{mg} / \mathrm{Kg}$ body weight have statistically significant $(* * p<0.005)$ while TC-III in all the three doses have highly significant anti-inflammatory effect $(* * * p<0.0001)$ with reference to normal saline $(10 \mathrm{~mL} / \mathrm{Kg})$ as control and Ketoprofen $10 \mathrm{mg} / \mathrm{Kg}$, as reference standard. The doses of the three compounds were selected on the bases of average doses of the legend (drug) reported in literature.

\section{Evaluation of anti-nociceptive activity}

\section{Hot plate (thermal) test in mice}

The hot plate tests were found negative for the three test compounds the data is, therefore, not reported.

Acetic acid induced writhing test in mice

The data of anti-nociceptive activities, acetic acid induced writing test, of the test compounds (TCI, -II \& -III) with reference to normal saline $10 \mathrm{~mL} / \mathrm{kg}$ as control and Diclofenac $10 \mathrm{mg} / \mathrm{Kg}$ as reference standard, depicted, statistically, that the results of the three test compounds were highly significant $(* * * p<0.001)$ [Fig. 2]. The result also showed that there was a direct relation of percent pain inhibition with increase in dose of the test compounds.

\section{Anti-pyretic evaluation study}

The statistical analysis of the data of Brewer's yeast induced pyrexia test revealed that antipyretic activities of the test compounds were highly significant $(* * * p<0.0001)$ in all the tested doses as compared to control (normal saline $10 \mathrm{~mL} / \mathrm{Kg}$ ) and Paracetamol reference standard (150mg/Kg body weight) [Fig. 3]. 


\section{Molecular docking simulations}

In order to get validated and accurate binding modes and binding affinities of the test compounds, flurbiprofen was used as a reference ligand to determine its RMSD value. RMSD value of reference compound was found to be 0.49 , which is a satisfactory score for validation. The analysis of the docking data revealed that the best scoring conformations of the TC-I, -II and -III were found much closer to the best scoring confirmations of flurbiprofen (Figs. 4 to 7). All the test compounds showed considerable molecular interactions with main binding pocket of the enzyme. The binding energy of protein-ligand interactions are given in Table 2.

\section{DISCUSSION}

Molecular docking analysis focused on COX2 enzyme gave reasonable explanation of different anti-inflammatory activities of test compounds. The carbonyl oxygen and nitrogen of the hydrazide substitute of TC-I were involved in hydrogen binding with Tyr 355 with hydrogen bond energy $2.5 \mathrm{kcal} / \mathrm{mol}$ each, unlike flurbiprofen (standard used) although both the compounds anchored in the same pocket. The overall binding energy of TC-I was $-96.862 \mathrm{kcal} / \mathrm{mol}$. The inhibition was strong but not significantly increased. TC-II fit in the binding pocket anchoring on the Try355 and Arg120 residues having similar hydrogen bonding energy value of $-2.5 \mathrm{kcal} / \mathrm{mol}$ while the overall binding energy was $-103.301 \mathrm{kcal} / \mathrm{mol}$. TC-III also anchored via Try355 and Arg120 residues with Try355 hydrogen binding energy as $-1.043 \mathrm{kcal} / \mathrm{mol}$ less than values of hydrogen bonds of the TCI and TC-II. 
The most favorable confirmations of the test compounds when combined in the binding site of COX-2 receptor, it revealed that all the test compounds packed in the same docking positons with almost similar behavior (21). The carbonyl moiety of TC-I and -III and the oxygen of ethoxymoiety of TC-II anchored on both $\operatorname{Arg}_{120}$ and $\operatorname{Tyr}_{355}$ (1st anchoring site), via hydrogen bonding interactions with in a narrow range of binding length difference (Table 2) and all were found considerable superimposable at anchoring site of the binding pocket (22) Figure 8.

The opposite side of the carbonyl group of the test compounds and flurbiprofen (i.e. the second phenyl ring of TC-I and TC-II and the isobutyl group of TC-III) were oriented in a hydrophobic cleft, $2^{\text {nd }}$ anchoring site, lined with Leu352, Ser530, Val523, Try384, Phe381, Tyr385, Met522, Gly526 and Trp387, residues (22). The entire test compounds showed good binding energies.

\section{CONCLUSION}

As the flurbiprofen has more selectivity towards COX2, its hydrazide analogue (TC-III) has shown highly significant anti-inflammatory activity in vivo followed by high binding energy / score. While the ibuprofen and naproxen being equipotent for both COX1/COX2 and their analogues (TC-I and TC-II, respectively) have shown inhibition of both isomers in vivo. It was observed that by the addition of hydrazide group there is no change in COX2 selectivity of TC-I and -II, but their peripheral analgesic and antipyretic activities were statistically highly significant. TC-II have also shown statistically significant anti-inflammatory activity as well. The docking result revealed promising molecular interactions (docking score / energies) of the compounds in the binding pocket, especially with Arg-120 and Try-355 amino acids residue of COX2 protein, which is one 
of the explanations for highly significant pharmacological activities, especially anti-inflammatory and analgesic activities of the TCs.

\section{ACKNOWLEDGEMENTS}

This research project was totally self-financed by the PhD research scholar SMA Halimi. The authors are thankful of PolyFine ChemPharma (Pvt.) Ltd. Hayatabad Industrial Estate, Peshawar, Khyber Pakhtunkhwa, Pakistan for provision of Ibuprofen, Flurbiprofen and Naproxen for the project.

\section{AUTHORS' NOTE}

SMA Halimi, PhD Research Scholar, has designed and conducted the whole research and wrote the paper. Muhammad Saeed conceived paper, supervise the research work as PhD supervisor of the research scholar, critically revised manuscript and approved final version. K Muhammed Ahmed guided, facilitated the synthesis of analogues and interpretation of its characterization data. Safi Ullah provided assistance in synthesis, characterization and pharmacological evaluation. The authors declare that they have no conflicts of interest. 


\section{REFERENCES}

1. Wlodawer A. Rational Approach to AIDS Drug Design Through Structural Biology. Annu Rev Med 2002; 53: 595-614.

2. Schneider G, Fechner U. Computer-based de novo design of drugs-like molecules. Nat Rev Drug Discov 2005; 4: 649-663.

3. Vane JR Inhibition of prostaglandin synthesis as a mechanism of action for aspirin-like drugs. Nat New Biol 1971; 43: 232-5.

4. Vane JR. The fight against rheumatism: from willows bark to COX-1 sparing drugs. J. Physiol Pharmacol 2000; 51: 573-86.

5. Kujubu DA, Herschman HR. Dexamethasone inhibits mitogen induction of the TIS10 prostaglandin synthase/cyclooxygenase gene. J Biol Chem 1992; 267: 7991-94.

6. Green GA. Understanding NSAIDs: from aspirin to COX-2. Clin Cornerstone 2001; 3: 5059.

7. Harrington PJ, Lodewijk E. Twenty years of Naproxen technology. Org Process Res and Devel 1997; 1: 72-6.

8. Brogden RN, Heel RC, Speight TM, Avery GS. Flurbiprofen: a review of its pharmacological properties and therapeutic use in rheumatic diseases. Drugs, 1979; 18: $417-38$.

9. Halford GM, Lordkipanidze M, Watson SP. 50th anniversary of the discovery of ibuprofen: an interview with Dr Stewart Adams. Platelets, 2012; 23: 415-22.

10. Kubinyi H. In Success stories of Computer-aided Design, (Ed: by S Ekins), Johan Wiley and Sons Inc, USA 2006, pp 377. 
11. Reid EE. Esterification A review of the recent past and a look towards the future. Indust \& Eng Chem 1937; 29: 1344-50.

12. Khan KM, Rasheed M, Zia-Ullah, Hayat S, Kaukab F, Choudhary MI, Atta-ur-Rahman, Perveen S. Synthesis and in vitro leishmanicidal activity of some hydrazides and their analogues. Bioorg Med Chem 2003; 11: 1381-87.

13. Bruce RD. An Up-and-Down Procedure for Acute Toxicity Testing. Toxicol Sci 1985; 5: $151-7$.

14. Winter A, Riselay EA, Nuss GW. Carrageenan induced edema in the hind paw of the rats as an assay for anti-inflammatory drugs. Proc Soc Exp Biol Med 1962; 111: 544-7.

15. Koster RR, Anderson M, De-Beer EJ. Acetic acid for analgesic screening. Federation proceedings 1959; 18: 412.

16. Eddy NB, Leimbacg D. Synthetic analgesics. II. Dithienylbutenyl- and dithienylbutylamines. J Pharmacol Exp Ther 1953; 107: 385-93.

17. Bottcher, Schweizer A, Glatt M, Werner H. A sulphonamido-indanone derivative CGP 28237 (ZK 34228), a novel non-steroidal anti-inflammatory agent without gastro-intestinal ulcerogenicity in rats. Drugs Exp Clin Res 1987; 13: 237-45.

18. Rowlinson SW, Kiefer JR. Prusakiewicz JJ, Pawlitz JL, Kozak KR et al. A novel mechanism of cyclooxygenase-2 inhibition involving interactions with Ser-530 and Tyr385. J Biol Chem 2003; 278: 45763-45769.

19. Ali G, Subhan F, Wadood A, Khan A, Ullah N et al. Pharmacological evaluation, molecular docking and dynamics simulation studies of salicyl alcohol nitrogen containing derivatives. Afr J Pharm Pharmacol 2013; 7: 585-96. 
20. Khan I, Nisar M, Ahmad M, Shah H, I Zafar et al. Molecular simulations of Taxawallin I inside classical taxol binding site of $\beta$-tubulin. Fitoterapia 2011; 82: 276-81.

21. Morris GM, Goodsell DS, Halliday RS, Huey R, Hart WE et al. Automated Docking Using a Lamarckian Genetic Algorithm and Empirical Binding Free Energy Function. J Comput Chem 1998; 19: 1639-62.

22. Savic S, Dilber SP, Marković BD, Milenković MT, Vladimirov SM et al. Docking Studies and $\alpha$-Substitution Effects on the Anti-Inflammatory Activity of $\beta$-Hydroxy- $\beta$ arylpropanoic Acids. Molecules, 2011; 16: 6645-55. 
Table 1: Hydrazide Analogues of Ibuprofen, Naproxen and Flurbiprofen

\begin{tabular}{|c|c|c|c|c|}
\hline Test Compound & Structure & IUPAC name & M.W & Formula \\
\hline TC-I & & $\begin{array}{l}\text { 2-(4-isobutylphenyl) } \\
\text { propanehydrazide }\end{array}$ & 220.311 & $\mathrm{C}_{13} \mathrm{H}_{20} \mathrm{~N}_{2} \mathrm{O}$ \\
\hline TC-II & & $\begin{array}{l}\text { (S)-2-(6- } \\
\text { methoxynaphthalen-2-yl) } \\
\text { propanehydrazide }\end{array}$ & 244.289 & $\mathrm{C}_{14} \mathrm{H}_{16} \mathrm{~N}_{2} \mathrm{O}_{2}$ \\
\hline TC-III & & $\begin{array}{l}\text { 2-(2-fluorobiphenyl-4-yl) } \\
\text { propanehydrazide }\end{array}$ & 258.291 & $\mathrm{C}_{15} \mathrm{H}_{15} \mathrm{FN}_{2} \mathrm{O}$ \\
\hline
\end{tabular}

Table 2: Binding energies of highest scored confirmations of the test compounds and reference legend through docking analysis

\begin{tabular}{lccccc}
\hline Test Compounds & $\begin{array}{c}\text { Binding } \\
\text { Energy } \\
\text { (kcal/mol) }\end{array}$ & \multicolumn{2}{c}{$\begin{array}{c}\text { Anchoring (Hydrogen } \\
\text { Bonding) Length }(\AA)\end{array}$} & \multicolumn{2}{c}{$\begin{array}{c}\text { Anchoring (Hydrogen } \\
\text { Bonding) Energy } \\
\text { (kcal/mol) }\end{array}$} \\
& & Arg120 & Tyr355 & Arg120 & Tyr355 \\
\hline Flurbiprofen (Ref. & -119.141 & 3.064 & 3.090 & -0.864 & -2.5 \\
Standard) & 2.963 & & -1.482 & -2.5 \\
TC-I & -96.862 & - & 2.747 & & -2.5 \\
TC-II & -103.301 & 2.797 & 2.892 & -2.5 & -2.5 \\
TC-III & -98.346 & 2.644 & 2.957 & -2.5 & -1.043 \\
\hline
\end{tabular}




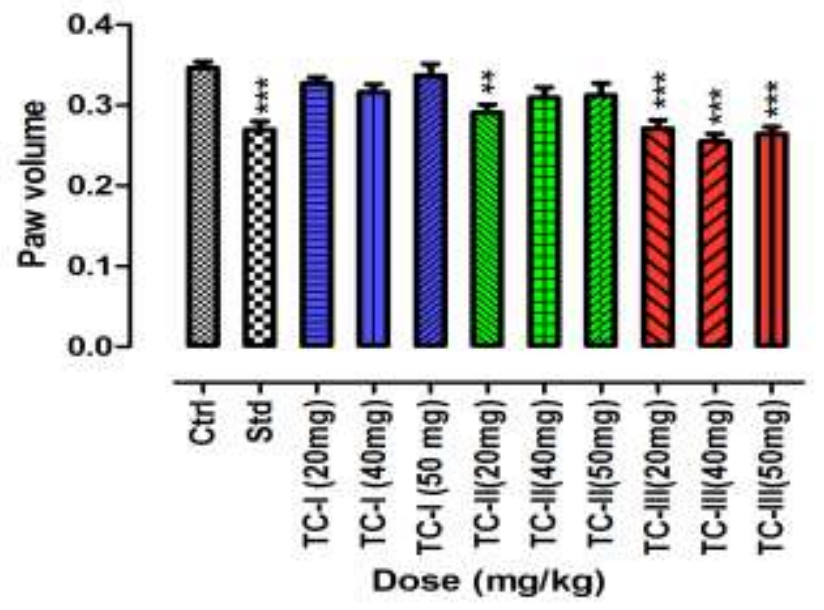

Fig. 1: Summarized comparison of anti-inflammatory activities of TC-I, TC-II and TC-III (20, 40, $50 \mathrm{mg} / \mathrm{kg}$ ) with control (normal saline $10 \mathrm{~mL} / \mathrm{kg}$ ) and reference standard (Diclofenac $10 \mathrm{mg} / \mathrm{Kg}$ ). Bars present as mean \pm SEM of $\%$ inhibition in paw volume, for a group of five animals $(n=6)$.

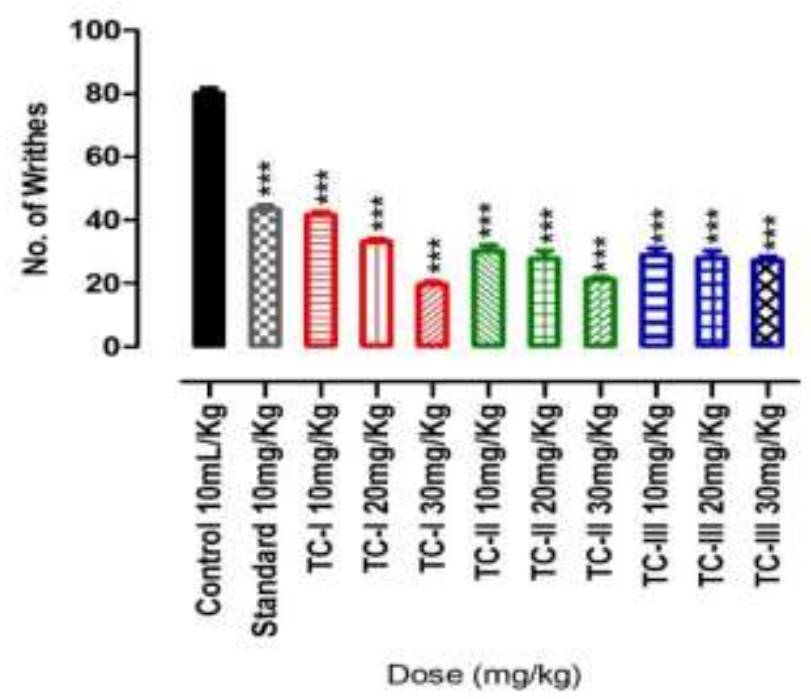

Fig. 2: Summarized comparison showing anti-nociceptive activities of TC-I, -II, \& -III (10, 20 and $30 \mathrm{mg} / \mathrm{kg})$ vs normal saline $(10 \mathrm{~mL} / \mathrm{Kg})$ and Diclofenac $10 \mathrm{mg} / \mathrm{kg}$ as reference standard. Bars present as mean \pm SEM of number of writhes, for a group of six animals. The effects are highly significant in all the three compounds $(* * * p<0.0001)$. 


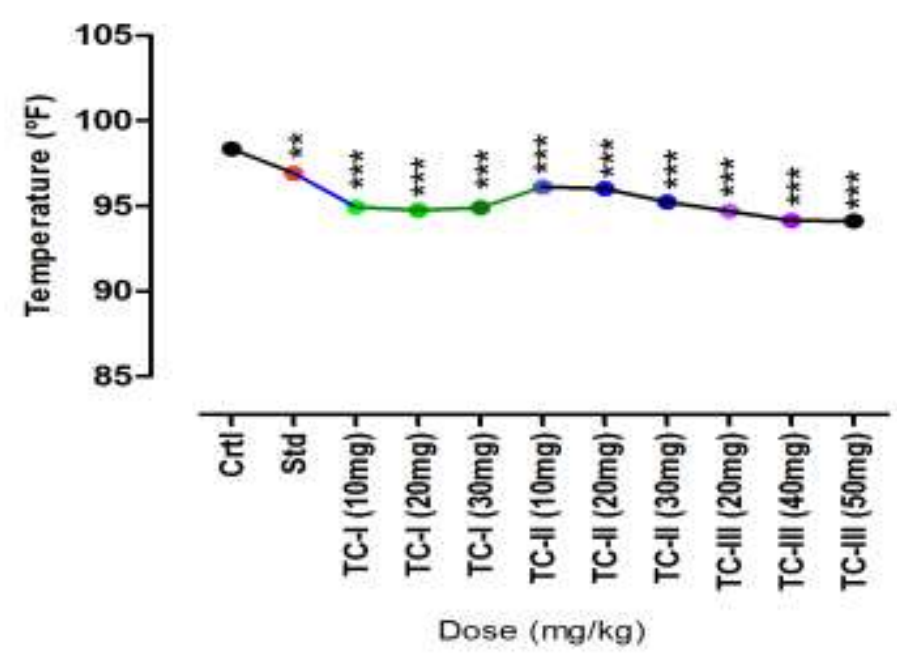

Fig.3: Summarized comparison showing antipyretic activity of different concentration of Test Compounds (TC-I, -II and -III) along with Control, normal saline $(10 \mathrm{~mL} / \mathrm{Kg})$ and reference standard (Paracetamol $150 \mathrm{mg} / \mathrm{kg}$ ). The antipyretic activities of the test compound were found highly significant $(* * * \mathrm{p}<0.0001)$.

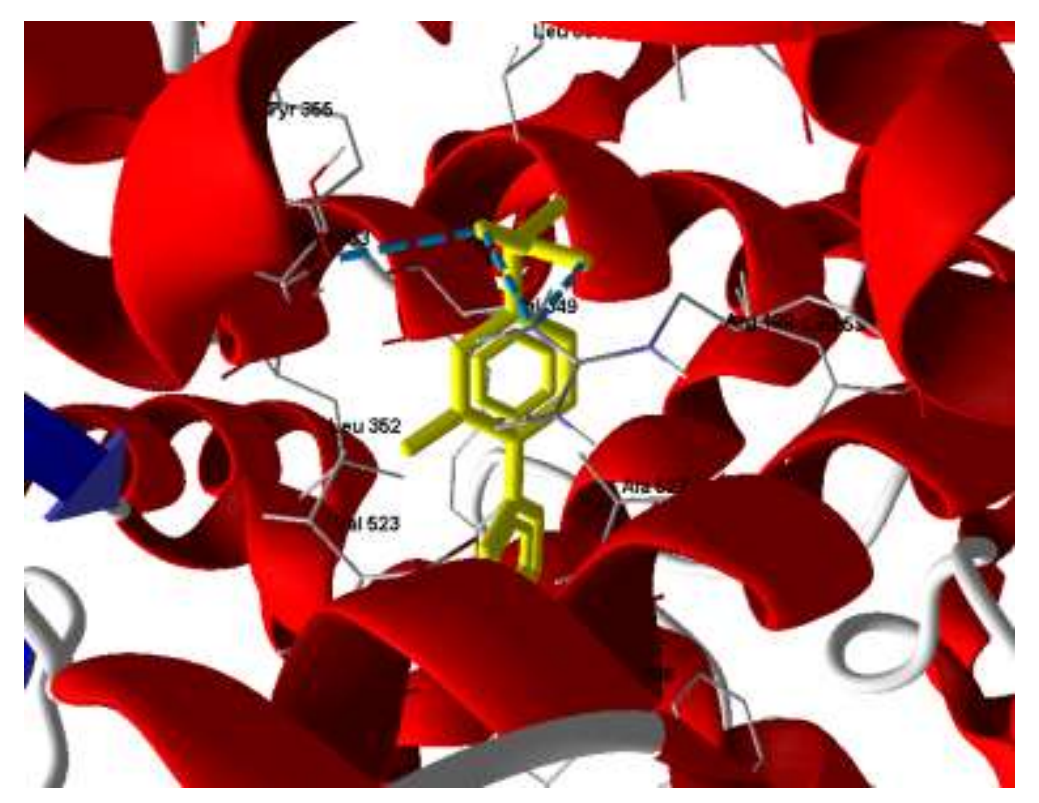

Fig. 4: Docking confirmations of Flurbiprofen (reference legend) in the binding pocket of COX2 enzyme protein. 


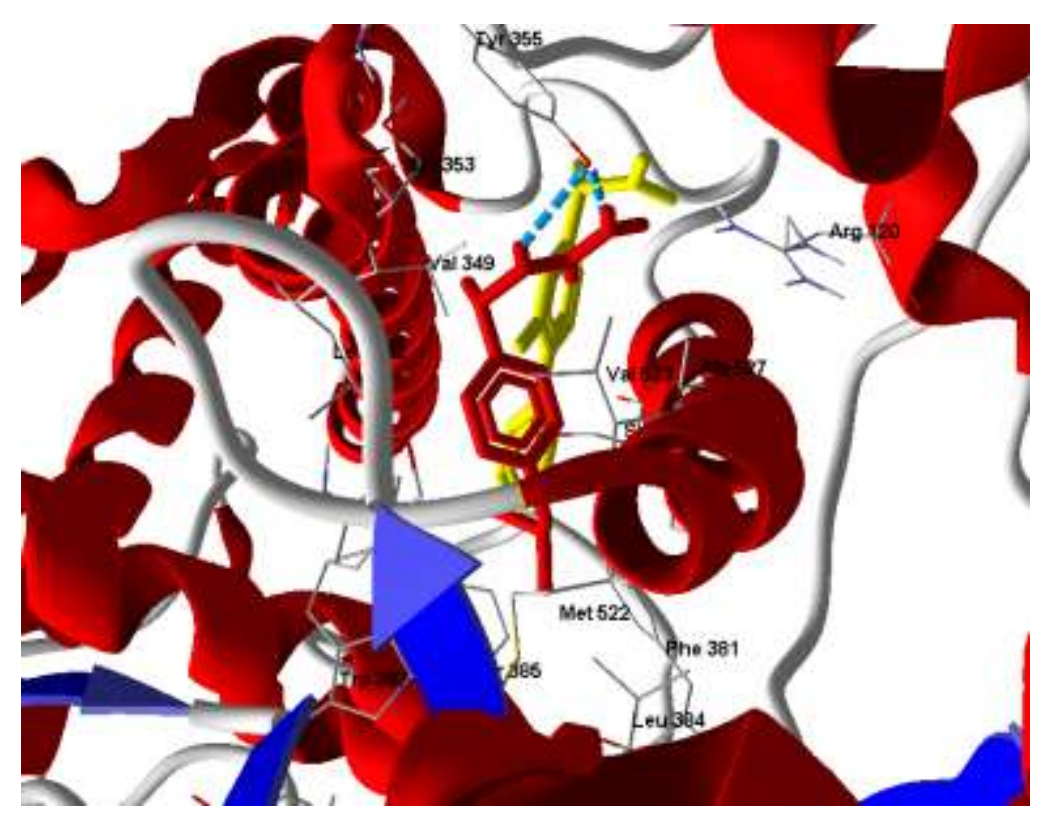

Fig. 5: Docking confirmations of TC-I in the binding pocket of COX2 enzyme protein.

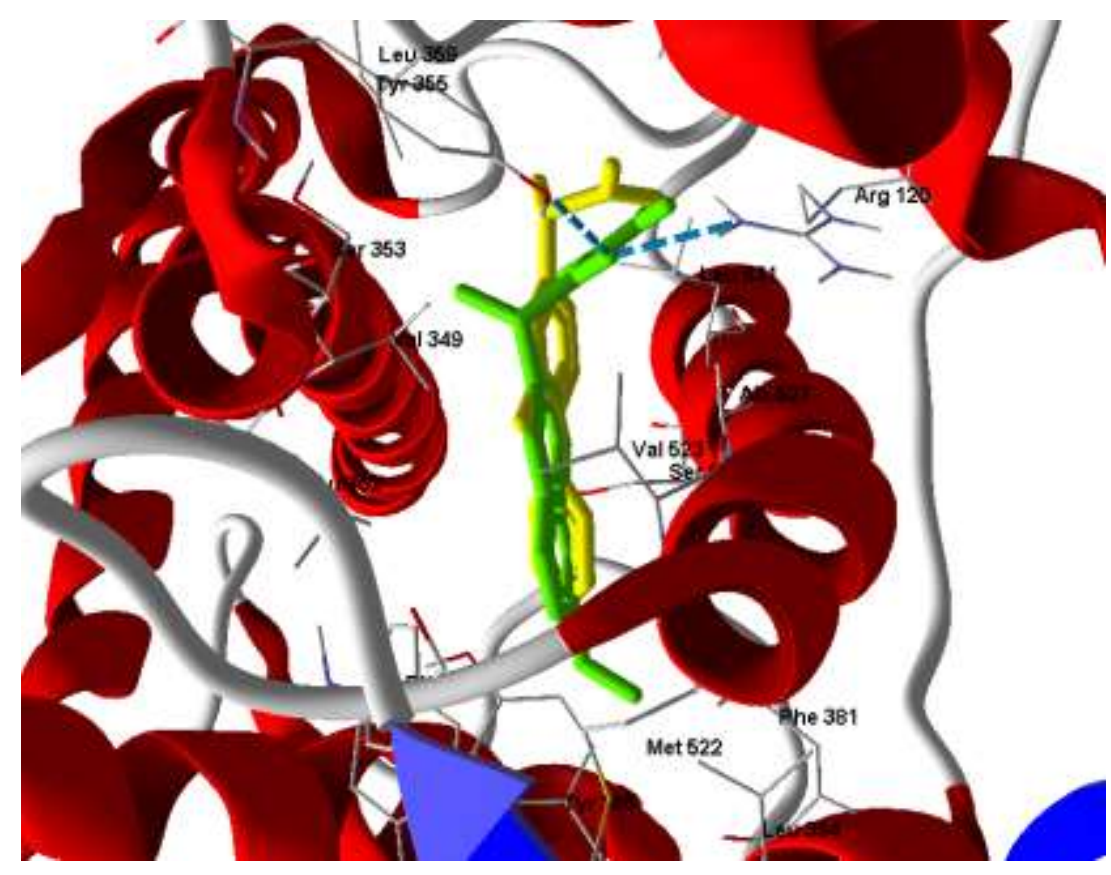

Fig. 6: Docking confirmations of TC-II in the binding pocket of COX2 enzyme protein. 


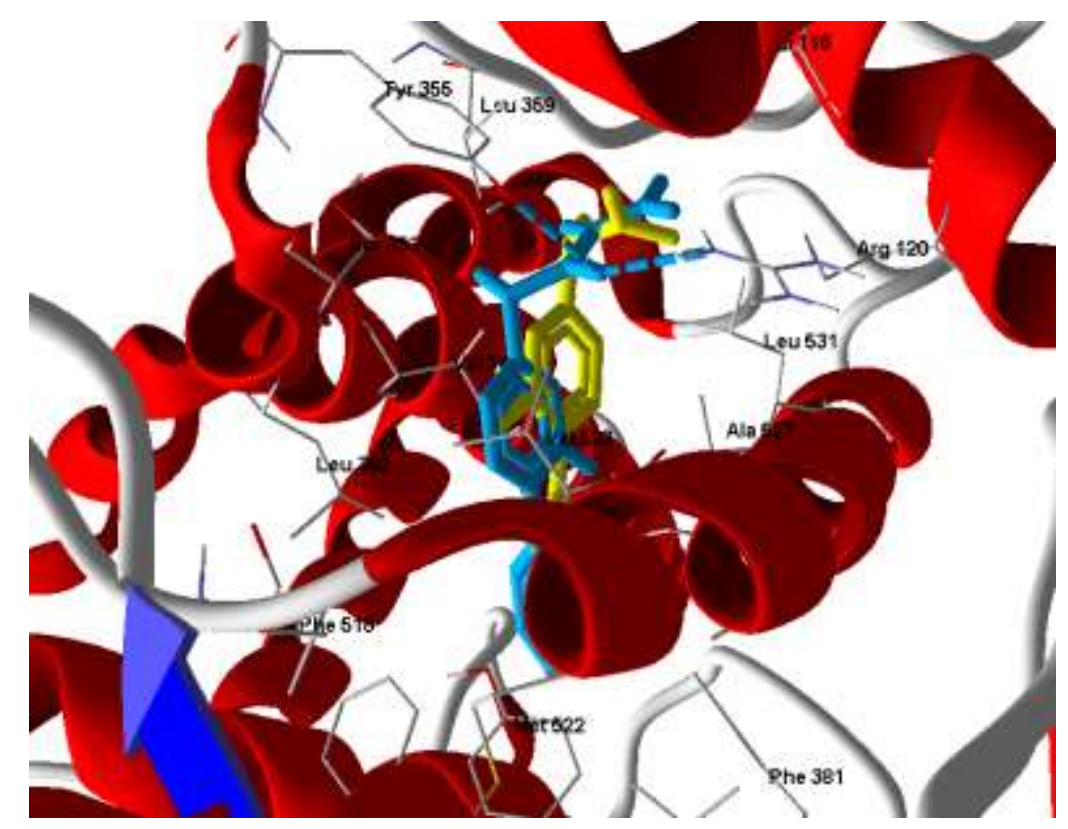

Fig. 7: Docking confirmations of TC-III in the binding pocket of COX2 enzyme protein.

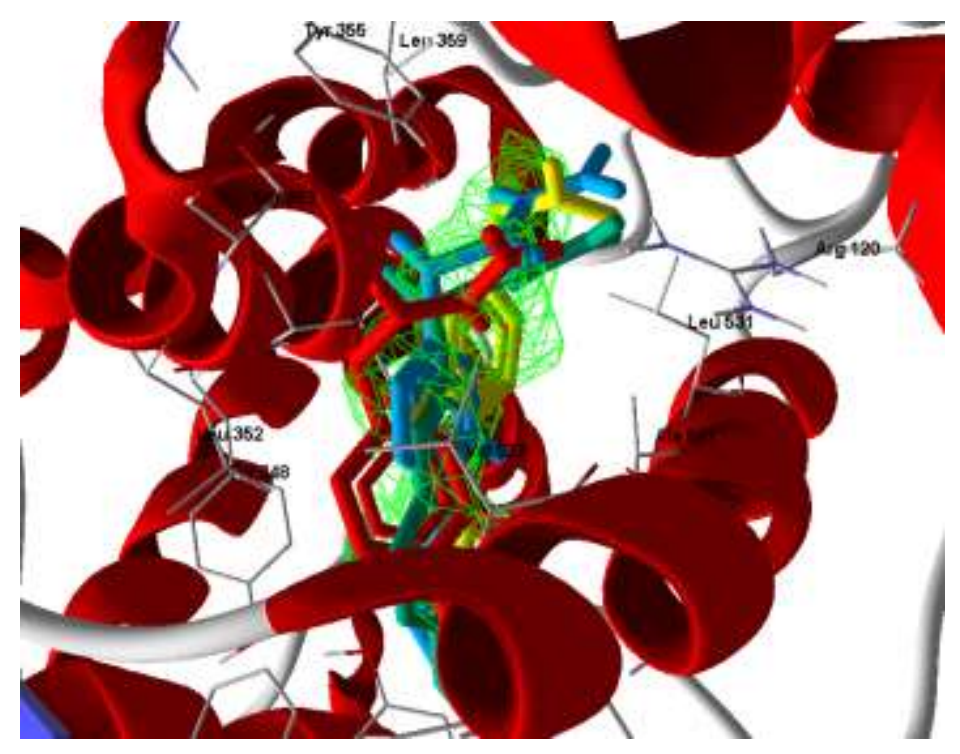

Fig. 8. Superimposition of test compounds TC-I (red), TC-II (green), TC-III (blue) and reference legend Flurbiprofen (yellow) in binding site. While the green mesh represents the binding cavity / pocket. 